\title{
Evaluation of Lipid Profile in Obese and Non-Obese Hypertensive Adult Patients Attended in Medicine Department of a Medical College Hospital of Bangladesh
}

\author{
Md Reaz Uddin Chowdhury ${ }^{1 *}$, Kazi Shanzida Akter², Sahedul Islam Bhuiyan³, Mainuddin Sohel1, \\ Mahbub Majumder ${ }^{4}$, Arif Mohammad Sohan', Mahfuzur Rahman', Muhammad Anwarul Kabir', \\ Zaman Ahmed1
}

\author{
${ }^{1}$ Abdul Malek Ukil Medical College, Noakhali, Bangladesh \\ ${ }^{2}$ Trauma Center, Feni, Bangladesh \\ ${ }^{3}$ Brahmanbaria Medical College, Brahmanbaria, Bangladesh \\ ${ }^{4}$ Cumilla Medical College, Cumilla, Bangladesh \\ ${ }^{5}$ Ad-Din Akij Medical College, Khulna, Bangladesh \\ Email: *mail2drreaz@gmail.com
}

How to cite this paper: Chowdhury, MdR.U., Akter, K.S., Bhuiyan, S.I., Sohel, M., Majumder, M., Sohan, A.M., Rahman, M., Kabir, M.A. and Ahmed, Z. (2020) Evaluation of Lipid Profile in Obese and Non-Obese Hypertensive Adult Patients Attended in Medicine Department of a Medical College Hospital of Bangladesh. World Journal of Cardiovascular Diseases, 10 , 520-544.

https://doi.org/10.4236/wjcd.2020.108052

Received: July 8, 2020

Accepted: August 14, 2020

Published: August 17, 2020

Copyright $\odot 2020$ by author(s) and Scientific Research Publishing Inc. This work is licensed under the Creative Commons Attribution International License (CC BY 4.0).

http://creativecommons.org/licenses/by/4.0/

\begin{abstract}
Background: By the dawn of this modern era of science, the prime challenge of physician is cardiovascular disease (CVD). The most important modifiable risk factors of CVDs are unhealthy diet, physical inactivity and tobacco use. The effects of unhealthy diet and physical inactivity include abnormal blood lipid, obesity and hypertension. We tried to evaluate and correlate the pattern of lipid profile in obese and non-obese hypertensive patients. Objectives: This study was conducted at medicine department of Cumilla Medical College Hospital. The principal aim was to evaluate the lipid profile in obese and non-obese adult hypertensive patients. Methodology: During this cross sectional analytical study, a total of 100 adult hypertensive patients were taken by purposive sampling. Among them 50 (group 1) patients were taken those were obese and 50 (group 2) patients taken those were non-obese according to BMI measurement on operational definition. Diagnosis of hypertension would be established with the help of ambulatory BP measurements two occasions few minutes apart. The staging of hypertension was done according to JNC7 Criteria. Morning blood samples were taken after $8-12$ hours of fasting and lipid profiles were done on authentic laboratories. The laboratory values were interpreted according to the operational definition of dyslipidaemia. The ethical research and review committee approved the study protocol and signed informed consent was obtained from the participants. The statis-
\end{abstract}


tics was analyzed using the IBM SPSS software of version 19.0. Statistical significance was set at $\mathrm{p}<0.05$. Results: Among the two groups, there were 56 (56\%) males and 44 (44\%) females. The mean age of group 1 (46.10 \pm 11.09$)$ was compared to that of group $2(45.5 \pm 10.6)$. Lipid profile abnormalities were significantly higher in the stage 2 hypertension (59.62\%) and stage 3 hypertension (66.66\%), higher in class 2 obese (100\%) and class 3 obese subjects (100\%), female hypertensive patients had significantly higher BMI than their male counterparts $\left(27.24 \pm 3.63 \mathrm{~kg} / \mathrm{m}^{2}\right.$ versus $\left.29.29 \pm 3.99 \mathrm{~kg} / \mathrm{m}^{2}\right)$, lipid profiles were higher in the female than male hypertensive patients $(63.33 \% \mathrm{vs}$ $55.35 \%)$ but only TC was statistically significant $(4.45 \pm 1.19 \mathrm{mmol} / \mathrm{l}$ versus $4.86 \pm 1.29 \mathrm{mmol} / \mathrm{l}, \mathrm{p}<0.05)$. Those who were obese had significant high TG $(\mathrm{p}<0.001)$, high TC $(\mathrm{p}<0.001)$ and high LDL-C $(\mathrm{p}<0.001) .38(76 \%)$ of the obese hypertensive patients had dyslipidaemia whereas 21 (42\%) of non-obese hypertensive patients had dyslipidaemia. In multivariate regression, TG was significantly and directly associated with BMI of subjects. Dyslipidaemia was more prevalent in the age group 30 - 59 of adult hypertensive patients. It showed that obese hypertensive patients had significantly higher SBP $(\mathrm{p}<0.001)$, DBP $(\mathrm{p}<0.001)$ than non-obese subjects. The mean TC $(4.83 \pm 0.95 \mathrm{mmol} / \mathrm{l}$ versus $4.15 \pm 0.57 \mathrm{mmol} / \mathrm{l}, \mathrm{t}=-9.70, \mathrm{p}<0.001), \mathrm{TG}(2.64$ $\pm 0.67 \mathrm{mmol} / \mathrm{l}$ versus $2.10 \pm 0.45 \mathrm{mmol} / \mathrm{l}, \mathrm{t}=-5.37, \mathrm{p}<0.001)$ and LDL-C $(3.00 \pm 0.82 \mathrm{mmol} / \mathrm{l}$ versus $2.44 \pm 0.53 \mathrm{mmol} / \mathrm{l}, \mathrm{t}=-9.11, \mathrm{p}<0.001)$ were also significantly higher among the hypertensive obese subjects. The mean HDL-C was however comparable in the two groups $(1.25 \pm 0.27 \mathrm{mmol} / \mathrm{l}$ versus $1.24 \pm$ $0.57 \mathrm{mmol} / \mathrm{l}, \mathrm{t}=-0.25, \mathrm{p}=0.08)$. Among the obese adult hypertensive subjects $38(76 \%)$ had at least one abnormal lipid parameter while $21(42 \%)$ of the non-obese hypertensive subjects had at least one lipid abnormalities. Elevated TG was therefore most frequent individual abnormality among both obese and non-obese adult hypertensive subjects. Conclusion: Dyslipidaemia is commonly associated with hypertension and in this study association between dyslipidaemia, obesity and hypertension was observed. Raised TC, LDL-C \& TG and low HDL-C were associated with increased incidence of hypertension.

\section{Keywords}

Lipid Profile, Dyslipidaemia, Obese, Non-Obese, Hypertension

\section{Introduction}

\subsection{Background}

Among the common non-communicable disorders, hypertension is emerging as a public health problem worldwide. It is now spreading in epidemic fashion in developing countries as well [1]. So by the dawn of this modern era of science, the prime challenge of a physician is cardiovascular disease [2]. According to WHO, cardiovascular disease is the number one cause of death globally [2]. Over $80 \%$ of cardiovascular disease deaths take place in low and middle eco- 
nomic countries like Bangladesh. By 2020, almost 20 million people will die from cardiovascular disease mainly from heart disease and stroke and they will remain the single leading cause of death [2]. Cardiovascular disease is caused by disease of heart, blood vessels and includes coronary heart disease, stroke, hypertension, peripheral vascular disease, rheumatic heart disease and heart failure [2]. The most important modifiable risk factors of CVDs are unhealthy diet, physical activity and tobacco use and the effects of unhealthy diet and physical inactivity include abnormal blood lipid, obesity etc. [3].

Abnormalities of serum lipid and lipoprotein levels (dyslipidaemia) are considered as major modifiable cardiovascular disease risk factors and identified as independent risk factors for essential hypertension [4] [5]. TC (total cholesterol), TG (triglycerides) and virtually all fraction of lipoproteins (HDL, LDL, VLDL) were frequently abnormal among hypertensive patients than in the general population. In general, people have been reported to have higher TG level and higher LDL due to their natural habitat of food. Concurrently the pattern of lipid profile in obese and non-obese adult hypertensive patients is not similar. Increased levels of atherogenic lipoproteins especially LDL but also IDL and possibly chylomicron remnants contribute to the development of atherosclerosis following chemical modification such as oxidation; the lipoproteins are no longer cleared by normal mechanism [6].

They trigger a self perpetuating inflammatory response during which they are taken up by macrophage to form foam cells-a hallmark of the atherosclerosis process. Low HDL cholesterol also predisposes to atherosclerosis [6]. The targeted total cholesterol (TC) is $<200 \mathrm{mg} / \mathrm{dl}$, triglycerides (TG) is $<150 \mathrm{mg} / \mathrm{dl}$, HDL cholesterol is $>50 \mathrm{mg} / \mathrm{dl}$ (for women $>55 \mathrm{mg} / \mathrm{dl}$ ), LDL cholesterol is $<100$ $\mathrm{mg} / \mathrm{dl}$, preferably $<70 \mathrm{mg} / \mathrm{dl}[7]$.

Hypertension is defined as trait as opposed to a specific disease and represents a quantitative rather than qualitative deviation from the normal [8]. Blood pressure is the force that drives blood through the blood vessels to supply oxygen and nutrients to the body's organ and tissues and carry away metabolism and waste materials [8]. Hypertension is classified into two groups; primary or essential and secondary hypertension. Primary hypertension is defined as rise of blood pressure of unknown cause. Secondary hypertension is due to disease of kidneys, endocrine and some other organs. Hypertension is graded into three stages based on the elevated BP [9]. Many cross sectional studies have suggested a link between plasma lipids and hypertension [10]. A few studies have prospectively examined the relationship between plasma lipids and the future development of hypertension. One prospective study demonstrates that higher level of plasma TC, non-HDL-C and TC/HDL-C ratio independently associated with a subsequent increased risk of incident of hypertension in apparently healthy obese patients [10]. Lipid and BP have been associated in several cross sectional studies. Thus plasma lipids may be useful in the identification risk for hypertension [11].

Obesity is noticed among all strata of the population in developing countries. 
It is one of the conventional risk factors for cardiovascular disease [12]. Obesity is defined when body mass index value exceeds the cut off value of $>30$. Amongst Asian adults, a BMI value of $>25$ is considered as obese [12]. Obesity is clearly associated with lipoprotein metabolism abnormalities and its assessment is extremely important in obese patient as they are more likely to develop cardiovascular disease. It is demonstrated that subjects with hypertension have a marked increase in the prevalence of hypercholesterolemia and hypertriglyceridemia [13].

\subsection{Rationale of the Study}

Hypertension is a common disease with serious consequences [1]. Dyslipidaemia is a major risk factor for hypertension [4]. On the other hand obesity is a newer problem rises worldwide [2]. There is a close correlation between hypertension, obesity and dyslipidaemia [4] [5]. Current guidelines for the management of hypertension and dyslipidaemia have focused on the need to set lipid targets in male and female gender to reduce the blood pressure and cardiovascular risks [14] [15]. So in our study, I tried to evaluate and correlate the lipid profile pattern in hypertensive obese and non-obese adult patients, the relation between obesity and hypertension, the relation between obesity, hypertension and dyslipidaemia.

\subsection{Research Questions/Hypothesis}

1) What is the pattern of lipid profile in obese and non-obese hypertensive patients?

2) Whether dyslipidaemia is related with obesity or hypertension?

\subsection{Objectives}

\section{General objectives:}

- To evaluate and correlate the lipid profile between obese and non-obese adult hypertensive patients.

\section{Specific objectives:}

1) To see the pattern of lipid profile in obese and non-obese hypertensive patients.

2) To evaluate the relation of lipid profile with obese and non-obese person.

3) To determine whether dyslipidaemia is related with obesity or hypertension.

4) To see the socio-demographic distribution of obesity.

5) To evaluate the lipid profile on different stages of hypertension.

\subsection{Review of Literature}

\subsubsection{Epidemiology of Hypertension}

The National Health and Nutritional Examination Survey (NHANES) which has been studying the health of representative samples of Americans since 1960 has provided data on the changing prevalence of hypertension and its control. According to this, the prevalence of hypertension decreased somewhat between 
1960 and 1991 [16] but the latest published analysis by the centre's for Disease Control and Prevention (CDC) based on data obtained in the period 1991 to 2002 , reported that prevalence had increased by 3.6 percent and that 28.6 percent of participants had hypertension [17].

Surveys in Europe show much higher rates of hypertension [18]. A comparison of six European countries data has found the highest rate in Germany (55 percent) and the lowest in Italy (38 percent) with France. The prevalence in Canada is very similar to that in the United States [18]. In the United States, hypertension is significantly more prevalent in African Americans than in whites. In the more recent NHANES survey [19], the prevalence in African Americans men was 38.6 percent where as white men were it was 29.6 percent; in women the prevalence was 44 percent for African Americans and 29.6 percent for whites [19]. The big issue here is whether the higher prevalence is genetic or environmental. There is a large literature showing that the rate as of hypertension in African living in traditional rural societies is relatively low but increases markedly when they move to the cities [20]. There are also differences in the prevalence of hypertension in other ethnic groups [21]. The incidence of hypertension in India is $5 \%-15 \%$ in the adult population against $10 \%-12 \%$ in the west [22]. In Bangladesh overall prevalence of Systolic and Diastolic hypertension in a study were 14.4 and 9.1 percent respectively [23]. In other study overall prevalence of Hypertension is $11.3 \%$ [24].

\subsubsection{Epidemiology of Dyslipidaemia}

One case control study shows that $30 \%$ patients of essential hypertension have elevated level of lipoprotein [25]. Familial dyslipidaemic hypertension occurs in $12 \%$ of subjects with essential hypertension [26]. The prevalence of coronary artery disease was often more than doubled among patients with concomitant dyslipidaemia and hypertension compared with patients with either condition alone [27]. Current guidelines for the management of hypertension and dyslipidaemia have focused on the need to set lipid targets to reduce the blood pressure and other cardiovascular risks [25].

\subsubsection{Mechanism of Essential Hypertension [14]}

Cardiac output and peripheral vascular resistance are the two determinants of arterial pressure. Cardiac output is determined by stroke volume and heart rate; stroke volume is related to myocardial contractility and to the size of the vascular compartment. Peripheral resistance is determined by functional and anatomic changes in small arteries and arterioles.

Intravascular volume: Vascular volume is a primary determinant of arterial pressure over long term. Sodium is predominantly an extracellular fluid volume. When $\mathrm{NaCl}$ intake exceeds the capacity of the kidneys to excrete sodium, vascular volume initially expands and cardiac output increases. The initial elevation of blood pressure in response to vascular volume expansion is related to an increase of cardiac output revert to normal. 
Autonomic nervous system: The autonomic nervous system maintains cardiovascular homeostasis via pressure, volume and chemoreceptor signals. Adrenergic reflexes modulate blood pressure over the short term and adrenergic function, in concert with hormonal and volume related effort contributed to the long term regulation of arterial pressure. The three endogenous catecholamines are epinephrine, nor epinephrine and dopamine. All three play an important role in cardiovascular volume.

Renin-angiotensin-aldosterone system: The renin-angiotensin-aldosterone system contributes to the regulation of arterial pressure primarily via the vasoconstrictor properties of angiotensin II and sodium retaining properties of aldosterone. There are three primary stimuli for renin secretion [28]. 1) Decreased $\mathrm{NaCl}$ transport in the thick ascending limb of henle. 2) Decreased pressure or stretch within the renal afferent arterioles. 3) Sympathetic nervous system stimulation of renin secreting cells via $B$ adrenoceptors. Once released into the circulation, active renin cleaves a substrate, angiotensinogen to form angiotensin which converts angiotensin I to angiotensin II. Acting primarily through angiotensin II, it secretes aldosterone by the adrenal zona glomerulosa and a potent mitogen stimulating vascular smooth muscle and myocyte growth.

\subsubsection{Measurement of Blood Pressure [29]}

Blood pressure should be measured with a well calibrated sphygmomanometer. The bladder width within the cuff encircles at least $80 \%$ of the arm circumference. Reading should be taken after the patient has been resting comfortably back supported in the sitting or supine position for at least 30 minutes after smoking or coffee intake. Hypertension is diagnosed when systolic blood pressure is consistently elevated above $140 \mathrm{~mm}$ of $\mathrm{Hg}$ or diastolic blood pressure is above $90 \mathrm{~mm}$ of $\mathrm{Hg}$, a single elevated blood pressure is not sufficient for diagnosis. The major exceptions of the rule are hypertensive presentation with equivocal evidence of life threatening end organ damage as seen in hypertensive emergency or in hypertensive urgency where blood pressure is $>220 / 120 \mathrm{~mm}$ of $\mathrm{Hg}$ but life threatening end organ damage is absent. In less severe cases, the diagnosis of hypertension depends on a series of measurement of blood pressure since reading can vary and to regress toward the mean with time.

\subsubsection{Classification of Hypertension [8]}

The following table provides a classification of blood pressure for adults aged 18 years of age or older. The classification based on the mean of 2 or more properly measured seated blood pressure reading on each of 2 or more office visits.

\begin{tabular}{ccc}
\hline Category & Systolic BP $(\mathrm{mmHg})$ & Diastolic BP $(\mathrm{mmHg})$ \\
\hline BP & & \\
Optimal & $<120$ & $<80$ \\
Normal & $<130$ & 85 \\
High normal & $130-139$ & $85-89$ \\
\hline
\end{tabular}


Continued

\begin{tabular}{ccc}
\hline Hypertension & & \\
Stage 1 (mild) & $140-159$ & $90-99$ \\
Stage 2 (moderate) & $160-179$ & $100-109$ \\
Stage 3 (severe) & $>180$ & $>110$ \\
\hline
\end{tabular}

\subsubsection{Clinical Features of Hypertension [30]}

Most patients with hypertension are asymptomatic. The high blood pressure usually has been noted during an incidental clinical examination. A proportion of patients present with a major complications of hypertension such as stroke or myocardial infarction but only a small number present with symptoms directly attributable to hypertension such as breathlessness or headache. Symptoms also have according to secondary causes of hypertension.

Investigations: Routine investigations of all hypertensive patients should include Urinalysis: Proteinuria, hyaline and granular cast may be found where there is renal disease of malignant hypertension. There is little or no protein in urine if patient with benign essential hypertension.

Blood urea: A raised level of urea suggests renal failure.

S. Creatinine: reflects the renal function.

ECG: This is usually normal in patients with mild hypertension but may show evidence of left ventricular hypertrophy.

Lipids: Although not directly related to blood pressure, an increased level of cholesterol is a risk factor for cardiovascular events.

\subsubsection{Dyslipidaemia [7]}

According to The National Cholesterol Education Programme (NCEP) Adult Treatment Panel (ATP III) guidelines LDL cholesterol optimal is $<100 \mathrm{mg} / \mathrm{dl}$; near optimal or above normal is $100-129 \mathrm{mg} / \mathrm{dl}$; borderline is $130-159 \mathrm{mg} / \mathrm{dl}$, high is $160-189 \mathrm{mg} / \mathrm{dl}$; very high is $>190 \mathrm{mg} / \mathrm{dl}$. Total cholesterol is desirable is $<200 \mathrm{mg} / \mathrm{dl}$; borderline high is $200-239 \mathrm{mg} / \mathrm{dl}$; high is $>240 \mathrm{mg} / \mathrm{dl}$.HDL cholesterol low is $<40 \mathrm{mg} / \mathrm{dl}$; high is $>60 \mathrm{mg} / \mathrm{dl}$. Triglycerides level $<150 \mathrm{mg} / \mathrm{dl}$ is normal; borderline high is $150-199 \mathrm{mg} / \mathrm{dl}$; high is $200-499 \mathrm{mg} / \mathrm{dl}$; very high is $>500 \mathrm{mg} / \mathrm{dl}$. Blood sample must be collected after 09 - 12 hours of fasting [7].

\section{Lipids and cardiovascular disease [31]}

Plasma lipoprotein levels are major modifiable risk factors for cardiovascular disease. Increased levels of atherogenic lipoproteins especially LDL but also IDL and possibly chylomicron remnants contribute to the development of atherosclerosis [7] [10]. Increased plasma concentration and reduced diameter favour subendothelial accumulation of these lipoproteins. Following chemical modification such as oxidation, the lipoproteins are no longer cleared by normal mechanisms. They trigger a self perpetuating inflammatory response during which they are taken up by macrophage to form foam cells-a hallmark of atherosclerotic process. Atherogenic lipoproteins also have an adverse effect on endothelial function. Low HDL cholesterol also predispose to atherosclerosis. 


\section{Lipid measurement [32]}

Abnormalities of lipid metabolism most commonly come to light following routine blood testing. Measurement of plasma cholesterol alone is not sufficient for comprehensive assessment. Levels of total cholesterol (TC), triglycerides (TG) and HDL cholesterol (HDL-C) should be obtained after an $8-12$ hour fast to permit the calculation of LDL cholesterol (LDL-C) according to Friedewald formula (LDL-C = TC-HDL-C-(TG/2.2) mmol/l). The formula becomes unreliable when TG level exceeds $4 \mathrm{mmol} / \mathrm{l}(350 \mathrm{mg} / \mathrm{dl})$. Nonfasting samples are unaffected in terms of TC and measured LDL-C but they differ in terms of TG and HDL-C.

\subsubsection{Classification of Dyslipidaemia [31]}

- Predominant hypercholesterolemia

- Familial hypercholesterolemia

- Hyper alphalipoproteinemia

- Predominant hypertriglyceridemia

- Lipoprotein lipase deficiency.

○ Familial hypertriglyceridemia.

- Mixed hyperlipidaemia

○ Familial combined hyperlipidaemia.

○ Dys betalipoproteinemia.

\section{Predominant hypercholesterolaemia}

Polygenic hypercholesterolemia is the most common cause of mild to moderate increase in LDL-C. Physical signs such as corneal arcus and xanthelasma may be found in this as well as other forms of lipid disturbance. Risk of cardiovascular disease is proportional to the degree of LDL-C elevation, together with other major risk factors particularly HDL-C.

\section{Familial hypercholesterolemia (FH):}

Familial hypercholesterolemia causes moderate to severe hypercholesterolemia with a prevalence of at least $0.2 \%$ in most populations. It is usually caused by a loss of function mutations in the LDL receptor gene, which results in an autosomal dominant pattern of inheritance. A similar syndrome can arise with loss of functions mutations in the legend-binding domain of Apo B100 or gain of function mutations in the ligand-binding domain of Apo B100 or gain of function mutations in the PCSK9 gene. The latter increases the activity of the PCSK9 protein, which is a sterol sensitive protease that targets the LDL receptor for degradation. Causative mutations can be detected in one of these three genes by genetic testing in about $70 \%$ of patients with $\mathrm{FH}$. Affected subjects suffer from severe hypercholesterolemia and premature cardiovascular disease.

\section{Hyperalphalipoproteinemia}

Hyperalphalipoproteinemia refers to increased levels of HDL-C. In the absence of an increase in LDL-C, this condition does not cause cardiovascular disease.

Predominant hypertriglyceridemia

Polygenic hypertriglyceridemia is the most common primary cause of TG 
elevation. It also commonly occurs secondary to excess alcohol, medications, type 2 diabetes, impaired glucose tolerance, central obesity or other manifestation of the insulin resistance syndrome. It is often accompanied by postprandial hyperlipidaemia and reduced HDL-C both of which may contribute to cardiovascular risk.

\section{Lipoprotein lipase deficiency}

Lipoprotein lipase deficiency is an infrequent autosomal recessive disorder due to hereditary deficiency of lipoprotein lipase or its co-factor. It causes massive hypertriglyceridemia that is resistant to drug treatment. It may result in hepatosplenomegaly, lipaemia retinitis and eruptive xanthoma.

\section{Familial hypertriglyceridemia}

Familial hypertriglyceridemia refers to dominant inheritance of pure hypertriglyceridemia. It has been suggested that it may represent a secondary response to impaired bile acid resorption and that it seems not to increase the risk of cardiovascular disease.

\section{Mixed hyperlipidaemia}

It is difficult to define the distinction between predominant hyperlipidaemia and mixed hyperlipidaemia quantitatively. The term mixed usually implies the presence of hypertriglyceridemia as well as increase in LDL or IDL. Treatment of massive hypertriglyceridemia may improve TG faster than cholesterol thus mimicking mixed hyperlipidaemia. Both components of hyperlipidaemia may contribute to the risk of cardiovascular disease.

\section{Dysbetalipoproteinaemia}

Dysbetalipoproteinaemia involves accumulation of roughly equal molar levels of cholesterol and TG. It is caused by homozygous inheritence of the apolipoprotein E2 alles which is the isoform least avidly recognized by the LDL receptor. Premature cardiovacular disease is common and it may result in the formation of palmar xanthoma, tuberous xanthoma or tendon xanthoma.

Miscellaneous and rare forms of hyperlipidaemia.

Tangier disease.

Apo A1 deficiency.

Fish eye disease.

LCAT deficiency.

Sitosterolemia.

\subsubsection{Epidemiology and Classification of Obesity [12]}

Obesity is widely regarded as a pandemic with potentially disastrous for human health. Over one quarter of adults in the UK were obese $\left(\mathrm{BMI}>30 \mathrm{~kg} / \mathrm{m}^{2}\right)$ in 2010. In developing countries, average national rates of obesity are low but these figures may disguise high rates of obesity in urban communities for example nearly one quarter of women in urban India are overweight. There is increasing public awareness of the health implications of obesity.

Obesity has adverse effects on both mortality and morbidity. Changes in mortality are difficult to analysis due to the confounding effects of lower body 
weight in cigarette smokers and those with other illnesses. It is suggested that obesity at age 40 years can reduce life expectancy by up to 7 years for non-smoker and by 13 years for smokers [6].

Classification of obesity [13]

\begin{tabular}{ccc}
\hline BMI $\left(\mathbf{k g} / \mathbf{m}^{2}\right)$ & Classification & Risk of obesity co-morbidity \\
\hline $18.5-24.9$ & Reference range & Negligible \\
$25.0-29.9$ & Overweight & Mildly increased \\
$>30.0$ & Obese & \\
$30.0-34.9$ & Class 1 & Moderate \\
$35.0-39.9$ & Class 2 & Severe \\
$>40.0$ & Class 3 & Very severe \\
\hline
\end{tabular}

The western pacific region office of WHO recommends that, amongst Asians the classification of obesity [13]:

\begin{tabular}{ccc}
\hline BMI $\left(\mathrm{kg} / \mathrm{m}^{2}\right)$ & Classifications & Risk of obesity co-morbidity \\
\hline $23-24.9$ & Overweight & Mildly increased \\
$>25.0$ & Obese & \\
$25-25.9$ & Class 1 & Moderate \\
$30-34.9$ & Class 2 & Severe \\
$>35$ & Class 3 & Very severe \\
\hline
\end{tabular}

\section{Methodology}

\subsection{Study Design}

Cross sectional type of analytical study.

\subsection{Place of Study}

Department of Medicine, Cumilla Medical College Hospital, Cumilla.

\subsection{Period of Study}

Nine months.

\subsection{Study Populations}

Adult Obese and non-obese patients suffering from hypertension.

\subsection{Sample Size: 100 Cases}

Sampling method: Sample size calculation-it is calculated by using Cochran's formula which considering $95 \%$ level of significance at $5 \%$ precision level and prevalence of dyslipidaemia is $30 \%$.

The formula is using $N=Z^{2}(p \times q) d^{2}$, here $N=$ minimum number of sample to be studied. 
$Z=$ Standardized normal value usually set at 1.96 which corresponds to $95 \%$ confidence interval.

$P=$ Prevalence of dyslipidaemia is $30 \%=0.30$

$q=1-p=1-0.30=0.69$

$d=$ degree of accuracy, 0.05 at $5 \%$ confidence level.

So, $N=327$

But due to limitation of budget and study period, my sample size was 100 .

\subsection{Inclusion and Exclusion Criteria}

\section{Inclusion criteria:}

1) Hypertensive patients of age $>18$ years.

2) Patients who gave informed written consent.

\section{Exclusion criteria:}

1) Known case of secondary hypertension.

1) Patients taking lipid lowering drugs.

3) Pregnancy.

\subsection{Operational Definitions}

\section{1) Hypertension}

Hypertension is said when SBP is $>140 \mathrm{~mm}$ of $\mathrm{Hg} \& \mathrm{DBP}$ is $>90 \mathrm{~mm}$ of $\mathrm{Hg}$. It is again graded into three stages. Grade 1 (mild) hypertension is SBP is 140 to 159 $\mathrm{mm}$ of $\mathrm{Hg} \& \mathrm{DBP}$ is 90 to $99 \mathrm{~mm}$ of $\mathrm{Hg}$. Grade 2 hypertension (moderate) is SBP is 160 to $179 \mathrm{~mm}$ of $\mathrm{Hg} \& \mathrm{DBP}$ is 100 to $109 \mathrm{~mm}$ of $\mathrm{Hg}$. Grade 3 hypertension (severe) hypertension is SBP is $>180 \mathrm{~mm}$ of $\mathrm{Hg} \& \mathrm{DBP}$ is $>110 \mathrm{~mm}$ of $\mathrm{Hg}$ [8].

\section{2) Obesity}

The western pacific region office of WHO recommends that amongst Asians, normal BMI (reference range-non obese) is 18.5 - $23 \mathrm{~kg} / \mathrm{m}^{2} \mathrm{BMI}>23.0$ - 24.9 $\mathrm{kg} / \mathrm{m}^{2}$ is overweight and BMI $>25.0 \mathrm{~kg} / \mathrm{m}^{2}$ is obesity. Class 1 obesity is BMI $25-$ $29.9 \mathrm{~kg} / \mathrm{m}^{2}$, Class 2 obesity is BMI $30-34.9 \mathrm{~kg} / \mathrm{m}^{2}$, Class 3 obesity is BMI > 35 $\mathrm{kg} / \mathrm{m}^{2}[12]$.

\begin{tabular}{cc}
\hline BMI $\left(\mathrm{kg} / \mathrm{m}^{2}\right)$ & Classifications \\
\hline $18.5-23$ & Normal \\
$23-24.9$ & Overweight \\
$>25$ & Obese \\
$25-29.9$ & Class 1 obesity \\
$30-34.9$ & Class 2 obesity \\
$>35$ & Class 3 obesity
\end{tabular}

\section{3) Dyslipidaemia}

Dyslipidaemia is the term given to abnormalities in blood lipid levels. According to the National Cholesterol Education Program (NCEP) Adult Treatment Panel 2 (ATP III) guidelines LDL cholesterol optimal is $<100 \mathrm{mg} / \mathrm{dl}$; near 
optimal or above normal is $100-129 \mathrm{mg} / \mathrm{dl}(2.59-3.34 \mathrm{mmol} / \mathrm{l})$; borderline is 130 - $159 \mathrm{mg} / \mathrm{dl}(3.37-4.12 \mathrm{mmol} / \mathrm{l})$; high is $160-189 \mathrm{mg} / \mathrm{dl}(4.15-4.90$ $\mathrm{mmol} / \mathrm{l})$; very high is $>190 \mathrm{mg} / \mathrm{dl}(>4.90 \mathrm{mmol} / \mathrm{l})$. Total cholesterol is desirable is $<200 \mathrm{mg} / \mathrm{dl}$ (5.18 mmol/l); borderline high is $200-239 \mathrm{mg} / \mathrm{dl}(5.18-6.18$ $\mathrm{mmol} / \mathrm{l})$; high is $>240 \mathrm{mg} / \mathrm{dl}(>6.22 \mathrm{mmol} / \mathrm{l})$. HDL cholesterol low is $<40 \mathrm{mg} / \mathrm{dl}$ $(1.00 \mathrm{mmol} / \mathrm{l})$; average is $40-50 \mathrm{mg} / \mathrm{dl}(1.00-1.3 \mathrm{mmol} / \mathrm{l})$ high is $>60 \mathrm{mg} / \mathrm{dl}(>$ $1.55 \mathrm{mmol} / \mathrm{l})$. Triglyceride level is $<150 \mathrm{mg} / \mathrm{dl}(<1.7 \mathrm{mmol} / \mathrm{l})$ is normal; $150-199$ $\mathrm{mg} / \mathrm{dl}(1.7-2.2 \mathrm{mmol} / \mathrm{l})$ is borderline high; $200-499 \mathrm{mg} / \mathrm{dl}(2.3-5.6 \mathrm{mmol} / \mathrm{l}$ is high. $>500 \mathrm{mg} / \mathrm{dl}(>5.6 \mathrm{mmol} / \mathrm{l})$ is very high. Blood sample collected after $9-12$ hours fasting [7].

\subsection{Flow Chart Showing the Sequence of Tasks}

Selection of cases (according to inclusion \& exclusion criteria) $\rightarrow$ Data collection $\rightarrow$ Data entry \& analysis by computer \& statistical software.

\subsection{Procedure of Preparing and Organizing Materials}

100 adult hypertensive patients were taken by purposive sampling method. Among them 50 were obese (group 1) and 50 are non-obese (group 2). Diagnosis of hypertension would be established with the help of ambulatory BP measurement on different occasions. Informed written consent would be obtained from the patients after full explanation of the details of the disease process. Lipid profile would be done from authentic laboratories. Findings of observation would be recorded or prescribed data collection form and compare them by statistical methods.

\subsection{Equipments to Be Used}

Adult Sphygmomanometer, Stethoscope, weight measuring machine, height measuring machine, measuring tape, Computer with internet access \& printer etc.

\subsection{Procedure of Data Analysis of Interpretation}

After collection, data would be edited, analyzed in a computer by Statistical package for social science (SPSS version-19). Assistance of a statistician would be taken.

\subsection{Time Table}

January 2018 to September 2018.

\subsection{Dissemination of Findings}

Implement research finding in practice both because of a growing awareness of the gap between clinical practice and the findings of research and also because of the need to show that investment in research results in benefits for patients.

\subsection{Ethical Implications}

The aims and objectives of the study along with its procedure, method risks and 
benefits of the study would be explained to the patients in easily understandable local language and the informed consent would be taken from the patient or legal guardian. It would be assured that all information and records would be kept confidential and the procedure would be helpful for both the physicians and the patients in making rational approach of case management. Permission from ethical committee of Comilla Medical College Hospital was taken.

\section{Result}

Among the two groups, there were 56 (56\%) males and 44 (44\%) females. The mean age of group $1(46.10 \pm 11.09)$ was compared to that of group $2(45.5 \pm$ 10.6). Lipid profile abnormalities were significantly higher in the stage 2 hypertension (59.64\%) and stage 3 hypertension (66.66\%), higher in class 2 obese $(100 \%)$ and class 3 obese (100\%) subjects, female hypertensive patients were significantly higher BMI than their male counterparts $\left(27.24 \pm 3.62 \mathrm{~kg} / \mathrm{m}^{2}\right.$ versus $\left.29.29 \pm 3.99 \mathrm{~kg} / \mathrm{m}^{2}\right)$, lipid profile were higher in the female than male hypertensive patients $(63.33 \%$ vs $55.35 \%)$ but only TC was statistically significant ( $4.45 \pm$ 1.19 versus $4.86 \pm 1.29, \mathrm{p}<0.05)$, among female patients higher in the housewife. Those who are obese had significant high TG $(\mathrm{p}<0.001)$, high TC $(\mathrm{p}<0.001)$ and high LDL-C ( $\mathrm{p}<0.001) .38(76 \%)$ of the obese hypertensive patients had dyslipidaemia and 12 (24\%) of the obese hypertensive patient had no dyslipidaemia. 21 (42\%) of non-obese hypertensive patients have dyslipidaemia and 29 (58\%) of nonobese hypertensive patient had no dyslipidaemia. In multivariate regression, TG was significantly and directly associated with BMI of subjects. Dyslipidaemia was more prevalent in the age group 30 - 59 of adult hypertensive patients. It showed that obese hypertensive patients had significantly higher SBP $(\mathrm{p}<0.001)$, DBP $(\mathrm{p}<0.001)$ than non-obese subjects. The mean TC $(4.83 \pm 0.95$ $\mathrm{mmol} / \mathrm{l}$ versus $4.15 \pm 0.57 \mathrm{mmol} / \mathrm{l}, \mathrm{t}=-9.70, \mathrm{p}<0.001), \mathrm{TG}(2.64 \pm 0.67 \mathrm{mmol} / \mathrm{l}$ versus $2.10 \pm 0.45 \mathrm{mmol} / \mathrm{l}, \mathrm{t}=-5.4, \mathrm{p}<0.001)$ and LDL-C $(3.00 \pm 0.82 \mathrm{mmol} / \mathrm{l}$ versus $2.44 \pm 0.53 \mathrm{mmol} / \mathrm{l}, \mathrm{t}=-9.1, \mathrm{p}<0.001)$ were also significantly higher among the hypertensive obese subjects. The mean HDL-C was however comparable in the two groups $(1.25 \pm 0.27 \mathrm{mmol} / \mathrm{l}$ versus $1.24 \pm 0.57 \mathrm{mmol} / \mathrm{l}, \mathrm{t}=-0.3$, $\mathrm{p}=0.08)$. Among the obese adult hypertensive subjects $38(76 \%)$ had at least one abnormal lipid parameter while 21 (42\%) of the non-obese hypertensive subjects had at least one lipid abnormalities. Elevated TG was therefore most frequent individual abnormality among both obese and non-obese adult hypertensive subjects.

\section{Discussion}

In this study, serum TC, TG, LDL-C concentrations are significantly higher in hypertensive obese than in hypertensive non-obese subjects.

Table 1 and Table 2 shows that 100 adult hypertensive patients who are in between the age of 20 - 85 years and majority are 30 - 59 years of age $(72 \%)$ that is majority are young and middle aged. The mean age of them was $46.01 \pm 11.08$ 
Table 1. Age frequency of obese hypertensive subjects-Group $1(\mathrm{n}=50)$.

\begin{tabular}{cccccc}
\hline Age (yrs) & Frequency & Percent & $\begin{array}{c}\text { Maximum } \\
(\mathrm{yrs})\end{array}$ & $\begin{array}{c}\text { Minimum } \\
(\mathrm{yrs})\end{array}$ & $\begin{array}{c}\text { Mean (yrs) } \\
\text { SD }\end{array}$ \\
\hline $20-29$ & 04 & 08 & & & \\
$30-39$ & 07 & 14 & & & \\
$40-49$ & 17 & 34 & & & \\
$50-59$ & 14 & 28 & 85 & & \\
$60-69$ & 05 & 10 & & & \\
$>70$ & 03 & 06 & & & \\
All ages & 50 & $100 \%$ & & & \\
\hline
\end{tabular}

Among them majority are 30 to 59 years of age $(76 \%)$ that is majority are middle aged.

Table 2. Age frequency of non-obese hypertensive subjects-Group $2(n=50)$.

\begin{tabular}{cccccc}
\hline Age (yrs) & Frequency & Percent & Maximum & Minimum & Mean (yrs) SD \\
\hline $20-29$ & 04 & 08 & & & \\
$30-39$ & 06 & 12 & & & \\
$40-49$ & 15 & 30 & & & \\
$50-59$ & 13 & 26 & 78 & 20 & $45.5 \pm 10.6$ \\
$60-69$ & 07 & 14 & & & \\
$>70$ & 05 & 10 & & & \\
All ages & 50 & $100 \%$ & & & \\
\hline
\end{tabular}

Among them majority are 30 to 59 years of age $(68 \%)$ that is majority are middle aged.

and $45.5 \pm 10.6$. Dyslipidaemia is more common in 30 to 59 years of age group. In both obese and non-obese hypertensive group, 37 (37\%) patients are in stage 1 hypertension, $57(57 \%)$ are in stage 2 hypertension and $6(6 \%)$ patients are in stage 3 hypertension. In all stage majority of the patient are in between 30 to 59 years of age. The results of a study show that increased age is associated with a significant increase in the prevalence of hypertension [32]. This finding is consistent with our findings.

Another study shows the prevalence of hypertension among individual aged > 60 is $65.4 \%$ [14]. In this study, among 100 patients most are 30 to 59 years (72\%) of age group. The discrepancy may be due to the increased awareness of hypertension in middle aged people and aged people are neglected in our society because of low socio-economic condition.

Figure 1 shows out of 100 subjects, 56 (56\%) patients are male and 44 (44\%) patient are female. Out of 50 obese patients, 29 (58\%) patients are male, of them $20(68.96 \%)$ patients have dyslipidaemia and 21 (42\%) patients are female, of them 18 (85.71\%) female patient have dyslipidaemia. Out of 50 non-obese patients, $27(54 \%)$ patients are male and $23(46 \%)$ patients are female, of them 21 patients have dyslipidaemia, among them 11 (52.38\%) patients are male and 10 $(47.62 \%)$ patients are female. The percentage of male patients is higher than 

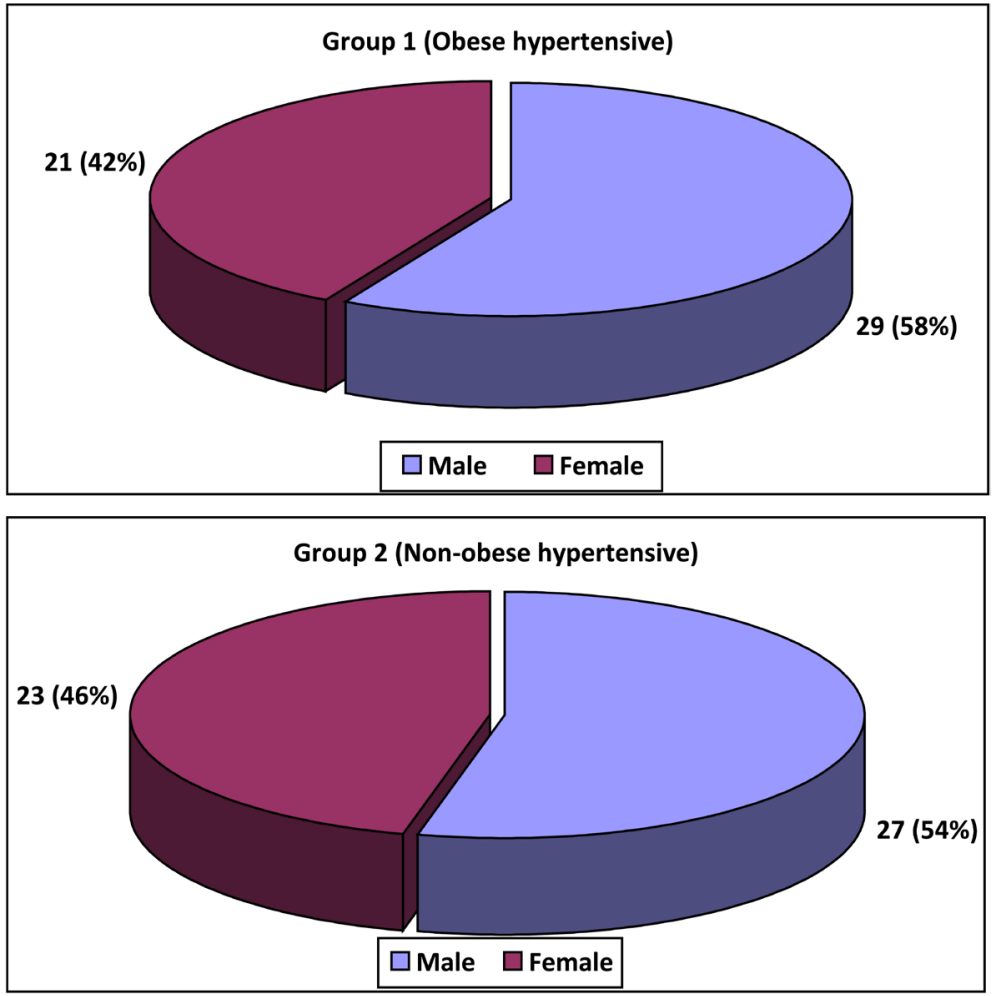

In this study out of 100 adult hypertensive patients 56 (56\%) are male and $44(44 \%)$ are female. Of 50 obese subjects $29(58 \%)$ patients are male and $21(42 \%)$ patients are female. Of 50 non-obese subjects, 27 (54\%) patients are male and $23(46 \%)$ patients are female.

Figure 1. Sex frequency of study subjects $(n=100)$.

female in both obese and non-obese hypertensive group (56\% vs $44 \%$ ). But in this study, dyslipidaemia is more common in women than in men of same age (63.33\% vs 55.35\%). Rulixin Y et al. showed that sex difference in the prevalence of hypertension and dyslipidaemia may be mainly attributed to the differences in dietary habits, life style choices, sodium and potassium intake, physical activity level and some genetic polymorphism [33]. Their finding is also similar to our findings.

Figure 2 and Figure 3 show among 100 patients (group 1 and group 2), 37 (37\%) patients are in stage 1 hypertension of them 21 (56.75\%) patients have dyslipidaemia, 57 (57\%) are in stage 2 hypertension of them 34 (59.65\%) patients have dyslipidaemia and $6(6 \%)$ patients are in stage 3 hypertension of them 4 (66.66\%) patients have dyslipidaemia. That is lipid abnormalities were higher in stage 2 and stage 3 hypertensive subjects. This finding was consistent with one earlier study done in Canada [26].

Figure 4 and Figure 5 show that, 52 (52\%) patients are urban and $48(48 \%)$ patients are rural dweller. Among 50 obese subjects, 38 (76\%) patient have dyslipidaemia of them $12(31.57 \%)$ patients are service holder, 7 (18.42\%) patients are businessman, $16(42.10 \%)$ patients are housewife, $2(5.26 \%)$ patients are farmer and $1(2.63 \%)$ is from other professions. Those $12(24 \%)$ patients have no dyslipidaemia, $6(50 \%)$ patients are service holder, 3 (25\%) patients are businessman, 2 
(16.66\%) patients are housewife and $1(8.34 \%)$ patient is farmer. Among 50 non-obese subject, $21(42 \%)$ patients have dyslipidaemia of them 8 (38.10\%) patients are service holder, $6(28.58 \%)$ are businessman, $6(28.58 \%)$ are house

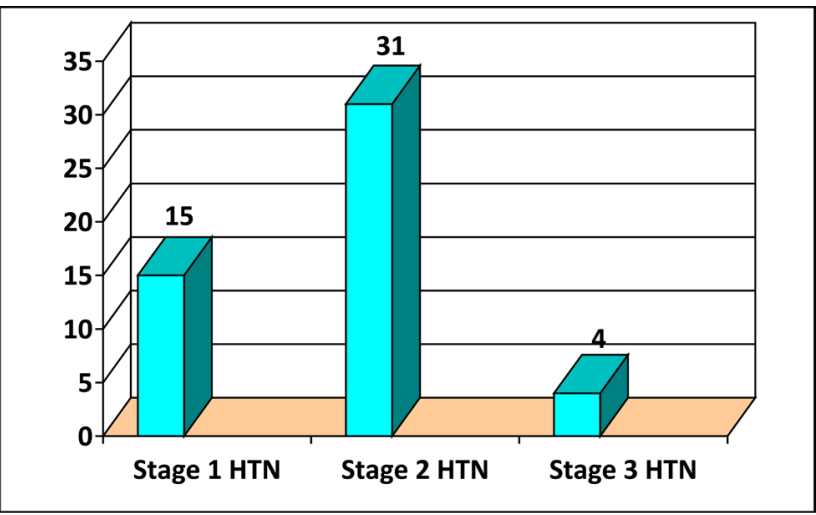

Figure 2. Stage of hypertension at presentation of obese hypertensive subjects-Group 1 $(\mathrm{n}=50)$.

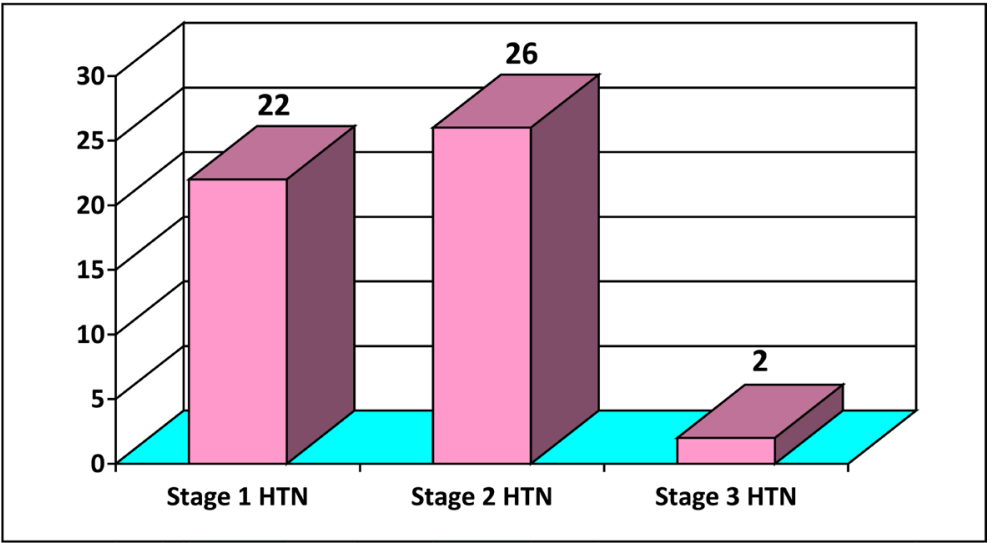

Figure 3. Stage of hypertension at presentation of non-obese hypertensive subjects-Group $2(\mathrm{n}=50)$.

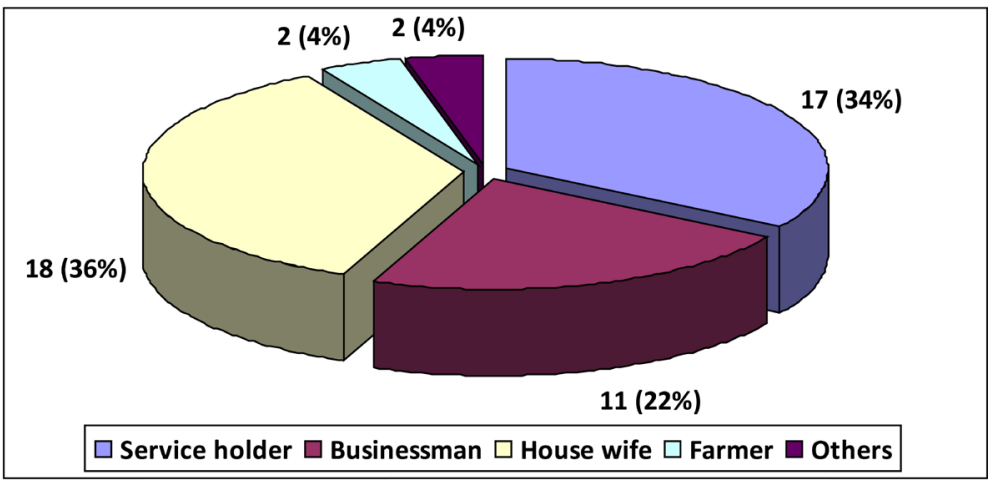

In this study, among 50 obese subjects, 38 (76\%) patients have dyslipidaemia of them 12 (31.58\%) patients are service holder, $07(18.42 \%)$ patients are businessman, $16(42.10 \%)$ patients are housewife, $01(2.63 \%)$ patient is farmer, $01(2.63 \%)$ from others occupation. Those $12(24 \%)$ patients have no dyslipidaemia, of them $05(41.66 \%)$ patients are service holder, $04(33.34 \%)$ patients are businessman, $2(16.67 \%)$ patients are housewife, $01(8.33 \%)$ patient is farmers.

Figure 4. Socio-demographic distribution of obese hypertensive subjects (Group 1). 


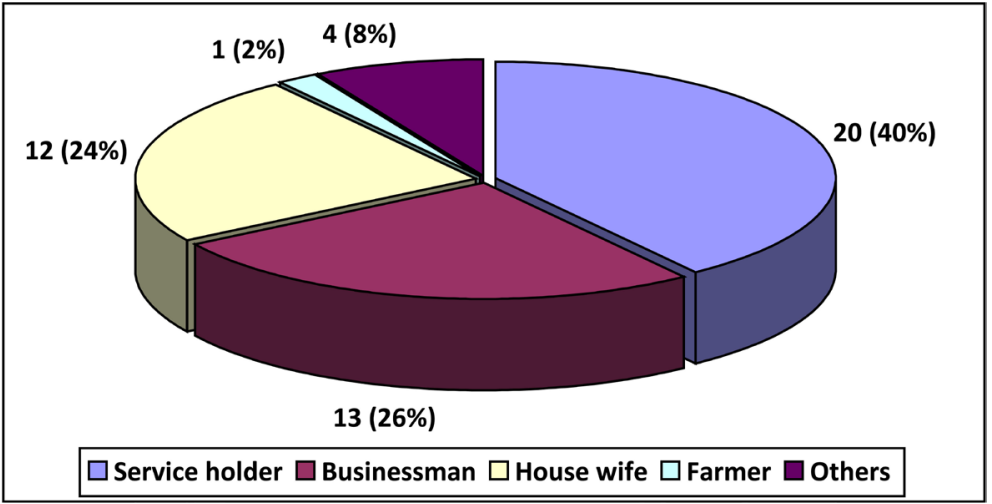

In this study, among 50 non-obese subjects, 21 patients have dyslipidaemia of them 08 (38.09\%) patients are service holder, $06(28.57 \%)$ patients are businessman, $06(28.57 \%)$ patients are housewife and 01 (4.76\%) patient from other occupation. Those 29 patients have no dyslipidaemia of them $12(41.37 \%)$ patients are serviceman, $07(24.13 \%)$ patients are businessman, $06(20.71 \%)$ patients are housewife and 04 (13.79\%) patients are from other professions.

Figure 5. Socio-demographic distribution of non-obese hypertensive subjects (Group 2).

wife and $1(4.8 \%)$ patient is from other professions. Those $29(58 \%)$ patients have no dyslipidaemia of them $12(41.38 \%)$ patient are serviceman, 7 (24.14\%) patient are businessman, $6(20.68 \%)$ patients are housewife and $4(13.80 \%)$ from other professions. So it showed that service holder and housewife have more prevalence of dyslipidaemia (74\%). In one study conducted in Bangladesh showed that sedentary workers have more prevalence of obesity as well as hypertension [34]. In this study prevalence of dyslipidaemia is more in obese hypertensive patients (76\%) than non-obese hypertensive patients $(42 \%)$. One similar study is showed significant difference of lipid abnormalities between obese and non-obese hypertensive patients [35].

Table 3 \& Table 4 show that obese hypertensive subjects have significantly higher SBP $(163.77 \pm 18.88$ versus $160.5 \pm 14.6, \mathrm{t}=-32.9, \mathrm{p}<0.001)$, DBP $(99.1 \pm$ 11.45 versus $98.44 \pm 10.45, \mathrm{t}=-28, \mathrm{p}<0.001)$ than non-obese hypertensive subjects. In one study Eaton et al. showed the similar type of findings [26].

Table 5 and Table 6 show that among 50 obese patients, 38 (76\%) patients have dyslipidaemia and remaining 12 (24\%) patients have no dyslipidaemia. Of them $11(28.94 \%)$ patient are in stage 1 hypertension, 23 (60.53\%) patients are in stage 2 hypertension and $04(10.53 \%)$ patient are in stage 3 hypertension. Those $12(24 \%)$ patients have no dyslipidaemia of them $04(33.34 \%)$ patients are in stage 1 hypertension and $8(66.66 \%)$ patients in stage 2 hypertension $(\mathrm{p}=0.04)$. Among 50 non-obese subjects, 21 (42\%) patients have dyslipidaemia of them 10 (47.61\%) patients are in stage 1 hypertension and 11 (52.38\%) patients are in stage 2 hypertension. Those 29 (68\%) patients have no dyslipidaemia of them 12 (41.37\%) patients are in stage 1 hypertension, 15 (51.72\%) patients are in stage 2 hypertension and $2(6.89 \%)$ patients are in stage 3 hypertension. $(\mathrm{p}=0.06)$. That is lipid abnormalities were higher in stage 2 hypertensive subjects. This finding was consistent with one earlier study done in Canada [26].

Table 7 shows that in this study among 100 patients 59 (59\%) patients have 
Table 3. Evaluation of blood pressure in obese and non-obese hypertensive subjects $(\mathrm{n}=$ 100).

\begin{tabular}{ccccc}
\hline BP & $\begin{array}{c}\text { Group 1 (Obese } \\
\text { hypertensive) } \\
\text { Mean } \pm \text { SD }\end{array}$ & $\begin{array}{c}\text { Group 2 (Non-obese } \\
\text { hypertensive) } \\
\text { Mean } \pm \text { SD }\end{array}$ & t & p-value \\
\hline SBP & $163.77 \pm 18.88$ & $160.50 \pm 14.60$ & -32.9 & $<0.001$ \\
DBP & $99.1 \pm 11.45$ & $98.44 \pm 10.45$ & -28 & $<0.001$ \\
\hline
\end{tabular}

Table 4. Distribution of BMI in obese hypertensive patients (Group 1).

\begin{tabular}{cccccc}
\hline BMI $\left(\mathrm{kg} / \mathrm{m}^{2}\right)$ & Number & Percent & Maximum & Minimum & Mean (SD) \\
\hline Class I & 40 & 80 & & & \\
Class II & 9 & 18 & 38 & 25.8 & $28.50(6.02)$ \\
Class III & 1 & 2 & & & \\
Total & 50 & 100 & & & \\
\hline
\end{tabular}

Table 5. Frequency of dyslipidaemia in different stages of BP in Obese hypertensive patients (Group 1, $\mathrm{n}=50$ ).

\begin{tabular}{cccccc}
\hline $\begin{array}{c}\text { Dyslipidaemia } \\
\text { status }\end{array}$ & $\begin{array}{c}\text { Frequency } \\
(\%)\end{array}$ & $\begin{array}{c}\text { Stage I } \\
\text { HTN (\%) }\end{array}$ & $\begin{array}{c}\text { Stage II } \\
\text { HTN (\%) }\end{array}$ & $\begin{array}{c}\text { Stage III } \\
\text { HTN (\%) }\end{array}$ & P value \\
\hline Present & $38(76 \%)$ & $11(28.94 \%)$ & $23(60.53 \%)$ & $04(10.53 \%)$ & 0.04 \\
Absent & $12(24 \%)$ & $04(33.34 \%)$ & $08(66.66 \%)$ & 00 & \\
\hline
\end{tabular}

Table 6. Frequency of dyslipidaemia in different stages of BP in Non-obese Hypertensive patients (Group 2, $\mathrm{n}=50$ ).

\begin{tabular}{cccccc}
\hline $\begin{array}{c}\text { Dyslipidaemia } \\
\text { status }\end{array}$ & $\begin{array}{c}\text { Frequency } \\
(\%)\end{array}$ & $\begin{array}{c}\text { Stage 1 } \\
\text { HTN (\%) }\end{array}$ & $\begin{array}{c}\text { Stage 2 } \\
\text { HTN (\%) }\end{array}$ & $\begin{array}{c}\text { Stage 3 } \\
\text { HTN (\%) }\end{array}$ & P value \\
\hline Present & $21(42 \%)$ & $10(47.61 \%)$ & $11(52.38 \%)$ & & 0.06 \\
Absent & $29(68 \%)$ & $12(41.37 \%)$ & $15(51.72 \%)$ & $02(6.89 \%)$ & \\
\hline
\end{tabular}

Table 7. Prevalence of dyslipidaemia in different stages of Hypertension in both groups $(\mathrm{n}=100)$.

\begin{tabular}{cccc}
\hline & Stage 1 HTN $(\mathrm{n}=37)$ & Stage 2 HTN $(\mathrm{n}=57)$ & Stage 3 HTN $(\mathrm{n}=\mathbf{6})$ \\
\hline Dyslipidaemia & $21(56.75 \%)$ & $34(59.64 \%)$ & $04(66.66 \%)$ \\
\hline
\end{tabular}

dyslipidaemia and remaining 41 (41\%) patients have no dyslipidaemia. Among patients of dyslipidaemia, 21 (56.75\%) patients in stage 1 hypertension, 34 (59.64\%) patients in stage 2 hypertension and $4(66.66 \%)$ patients in stage 3 hypertension. One case control study Bhavani BA et al. showed that $40.5 \%$ patients of hypertension have elevated level of lipoprotein and lipoprotein abnormalities tend to be more in patients with increase level of hypertension [25]. These findings correlate with our findings.

Table 8 shows that dyslipidaemia is more in patients who have higher BMI. The result of a study shows that increased BMI is associated with significant in- 
crease in the prevalence of hypertension and dyslipidaemia [35]. Recent findings from the Framingham Offspring [36] indicate that BMI is linearly related to the TC, LDL-C, TG concentrations and is however inversely related with HDL cholesterol. In this study correlation between dyslipidaemia and BMI was found as all class 2 and class 3 obese (100\%) subjects have dyslipidaemia.

Table 9 shows female hypertensive patients were significantly higher BMI than their male counterparts $(27.24 \pm 3.62$ vs $29.29 \pm 3.99)$ and the lipid profile were higher in the female than male hypertensive patients, only total cholesterol was statistically significant. ( $4.86 \pm 1.29 \mathrm{mmol} / \mathrm{l}$ vs $4.45 \pm 1.19 \mathrm{mmol} / \mathrm{l})$. So in our study interestingly females have significantly higher TC than their male counterparts. These findings do not correlate with the findings in an earlier study in Nigeria which showed that females have significantly higher TG than male [37].

Table 10 shows that obese hypertensive patients have significantly higher serum TC, TG, LDL-C concentration than non-obese subjects. This is consistent

Table 8. Prevalence of dyslipidaemia in different classes of obesity $(n=50)$.

\begin{tabular}{cccc}
\hline & Class 1 obesity $(n=40)$ & Class 2 obesity $(n=9)$ & Class 3 obesity $(n=1)$ \\
\hline Dyslipidaemia & $28(70 \%)$ & $9(100 \%)$ & $1(100 \%)$
\end{tabular}

Table 9. Sex related comparison of BMI and lipid profile in obese and non-obese hypertensive subjects $(\mathrm{n}=100)$.

\begin{tabular}{cccc}
\hline & Male $(\mathbf{n}=\mathbf{5 6})$ & Female $(\mathbf{n}=\mathbf{4 4})$ & p-values \\
\hline BMI $\left(\mathrm{kg} / \mathrm{m}^{2}\right)$ & $27.24 \pm 3.62$ & $29.29 \pm 3.99$ & $<0.05$ \\
TC $(\mathrm{mmol} / \mathrm{l})$ & $4.45 \pm 1.19$ & $4.86 \pm 1.29$ & $<0.05$ \\
TG $(\mathrm{mmol} / \mathrm{l})$ & $1.61 \pm 0.71$ & $1.69 \pm 0.63$ & $>0.05$ \\
HDL-cholesterol & $1.23 \pm 0.48$ & $1.38 \pm 0.53$ & $>0.05$ \\
LDL-cholesterol & $2.49 \pm 0.93$ & $2.71 \pm 0.98$ & $>0.05$ \\
\hline
\end{tabular}

This table shows female hypertensive patients were significantly higher BMI than their male counterparts $(27.24 \pm 3.62$ vs $29.29 \pm 4.79)$. Although the lipid profile was higher in the female than male hypertensive patients only total cholesterol was statistically significant $(4.86 \pm 1.29 \mathrm{mmol} / \mathrm{l}$ vs $4.45 \pm 1.19 \mathrm{mmol} / \mathrm{l}, \mathrm{p}<$ 0.05 ).

Table 10. Evaluation of Lipid profile of Obese and Non-obese hypertensive subjects $(\mathrm{n}=$ 100).

\begin{tabular}{ccccc}
\hline Variable & $\begin{array}{c}\text { Hypertensive obese } \\
\text { Mean } \pm \text { SD }\end{array}$ & $\begin{array}{c}\text { Hypertensive } \\
\text { (non-obese) }\end{array}$ & $\mathbf{t}$ & P value \\
\hline BMI $\left(\mathrm{kg} / \mathrm{m}^{2}\right)$ & $28.5 \pm 6.02$ & $20.5 \pm 3.4$ & -4.1 & $<0.001$ \\
TG & $2.64 \pm 0.67$ & $2.10 \pm 0.45$ & -5.4 & $<0.001$ \\
HDL-C & $1.25 \pm 0.27$ & $1.24 \pm 0.57$ & -0.3 & $=0.8$ \\
LDL-C & $3.00 \pm 0.82$ & $2.44 \pm 0.53$ & -9.1 & $<0.001$ \\
TC & $4.83 \pm 0.95$ & $4.15 \pm 0.57$ & -9.7 & $<0.001$ \\
\hline
\end{tabular}

The mean TC $(4.83 \pm 0.95$ versus $4.15 \pm 0.57, \mathrm{t}=-9.70, \mathrm{p}<0.001)$, TG $(2.64 \pm 0.67$ versus $2.10 \pm 0.45, \mathrm{t}=$ $-5.4, \mathrm{p}<0.001)$ and LDL-C $(3.00 \pm 0.82$ versus $2.44 \pm 0.53, \mathrm{t}=-9.11, \mathrm{p}<0.001)$ were also significantly higher among the hypertensive obese subjects. The mean HDL-C was however comparable in the two groups $(1.25 \pm 0.27$ versus $1.24 \pm 0.57, \mathrm{t}=-0.3, \mathrm{p}=0.08)$. 
with the earlier observation in other parts of the world [38]. The mean TC (4.83 \pm 0.95 versus $4.15 \pm 0.57, \mathrm{t}=-9.70, \mathrm{p}<0.001)$, TG $(2.64 \pm 0.67$ versus $2.10 \pm$ $0.45, \mathrm{t}=-5.4, \mathrm{p}<0.001)$ and LDL-C $(3.00 \pm 0.82$ versus $2.44 \pm 0.53, \mathrm{t}=-9.1, \mathrm{p}<$ $0.001)$ were also significantly higher among the hypertensive obese subjects. The mean HDL-C was however comparable in the two groups $(1.25 \pm 0.27$ versus $1.24 \pm 0.57, \mathrm{t}=-0.3, \mathrm{p}=0.08)$. This is unlike the finding of Kesteloot et al. who reported that TC, TG and LDL-C of hypertensive obese patients did not differ significantly from that of hypertensive non-obese subjects though hypertensive obese subjects tended to have a higher level of LDL-C, TG, TC [39].

Table 11 shows among the obese adult hypertensive subjects 38 (76\%) had at least one abnormal lipid parameter while 21 (42\%) of the non-obese hypertensive subjects have at least one lipid abnormalities. Isolated high TG was therefore most frequent individual abnormality among both obese and non-obese adult hypertensive subjects. The ATPIII guidelines recognize isolated elevated TG is a distinct form of dyslipidaemia but state that it is not common in general population [7]. Our data and those of Amoudu et al. however suggest that isolated high TG may be a relatively common baseline abnormality among the general population in this part of Nigeria [40]. The limitations of the study were the study is conducted in one center only, small sample size, risk factors other than dyslipidaemia are not considered.

\section{Conclusions}

- Dyslipidaemia is an important risk factor for hypertension and in this study association between dyslipidaemia and hypertension was observed.

- TC, TG and LDL-C were significantly higher among the obese hypertensive than non-obese hypertensive.

- Raised TC, LDL-C \& TG and low HDL are associated with increased incidence of hypertension.

- Dyslipidaemia is more prevalent among the patients having higher BMI.

- Isolated high TG is the most common abnormality in both obese and non-obese hypertensive patients.

Table 11. Prevalence of various serum lipid abnormalities among the study subjects $(\mathrm{n}=$ 100).

\begin{tabular}{ccc}
\hline Lipid abnormalities & Hypertensive obese (\%) & Hypertensive non-obese (\%) \\
\hline Elevated TC & $24(48 \%)$ & $17(34 \%)$ \\
Elevated LDL-C & $29(58 \%)$ & $14(28 \%)$ \\
Elevated TG & $35(70 \%)$ & $18(36 \%)$ \\
Low HDL-C & $32(64 \%)$ & $18(36 \%)$ \\
No lipid abnormality & $12(24 \%)$ & $29(58 \%)$ \\
One lipid abnormality & $16(32 \%)$ & $07(14 \%)$ \\
$>2$ lipid abnormality & $22(44 \%)$ & $14(28 \%)$ \\
\hline
\end{tabular}

Elevated TG was therefore most frequent lipid abnormality among both hypertensive obese and non-obese subjects. 
- Dyslipidaemia is major risk factor of atherosclerotic cardiovascular disease and also risk factor or association with other co-morbidities such as hypertension which is also another major modifiable risk factor of atherosclerotic cardiovascular disease. Dyslipidaemia presents among persons with higher BMI (obese) than non-obese persons.

\section{Limitation of the Study}

- The study is conducted in one center only.

- Small sample size.

- Risk factors other than dyslipidaemia are not considered.

\section{Recommendations}

As dyslipidaemia is an important risk factor for hypertension, lipid profile should be investigated thoroughly in hypertensive patients in medical practice.

- To control hypertension concomitant dyslipidaemia should be treated with appropriate lipid lowering drugs.

- As hypertension and dyslipidaemia are common in patients with having increased BMI. Weight reduction should be encouraged in hypertensive as well as normotensive patients.

- Doing the paper on a large scale multi-centric basis and maybe adding other risk factors of ischaemic heart disease in the study.

\section{Conflicts of Interest}

The authors declare no conflicts of interest regarding the publication of this paper.

\section{References}

[1] Nissinen, A., Bothing, S., Grenroth, H. and Lopez, A.D. (1988) Hypertension in Developing Countries. World Health Statistics Quarterly, 41, 141-154.

[2] World Health Organization. Cardiovascular Disease. http://www.who.int/health-topics/cardiovascular-diseases/\#tab=tab_1.html

[3] Badiuzzamam, M., Mohammed, F., Chowdhury, F., Bari, M., Alam, M. and Ahasan, H. (2012) Prevalence of Modiafiable Risk Factors among Stroke Patients in a Tertiary Care Hospital in Dhaka. Journal of Medicine, 10, 18-21.

[4] Kannel, W.B., Castelli, W.P., Gordon, T. and Mcnamara, P.M. (1971) Serum Cholesterol, Lipoprotein and the Risk of Coronary Heart Disease. The Framingham Study. Annals of Internal Medicine, 74, 1-12. https://doi.org/10.7326/0003-4819-74-1-1

[5] Williams, R.R., Hunt, S.C., Hopkins, P.N., et al. (1988) Familial Dyslipidemic Hypertension. Evidence from 58 Utah Families for a Syndrome Present in Approximately $12 \%$ of Patients with Essential Hypertension. Journal of American Medical Association, 259, 3579-3586.

https://doi.org/10.1001/jama.1988.03720240041032

[6] Onitiri, A.C., Sander, M. and Boyo, A.E. (1977) Serum Lipids and Lipoproteins in Healthy Africans. Clinica Chimica Acta, 81, 57-61. https://doi.org/10.1016/0009-8981(77)90413-2 
[7] Expert Panel on Detection, Evaluation, and Treatment of High Blood Cholesterol in Adults (2001) Executive Summary of the Third Report of the National Cholesterol Education Programme (NCEP) Expert Panel on Detection, Evaluation and Treatment of High Blood Cholesterol in adults(Adults Treatment Panel III). JAMA, 285, 2486-2497. https://doi.org/10.1001/jama.285.19.2486

[8] Chobanian, A.V., Bakris, G.L., George, L., et al. (2003) The Seventh Report of the Joint Committee on Prevention, Detection, Evaluation and Treatment of High Blood Pressure: The JNC 7 Report. JAMA, 289, 2560-2571.

https://doi.org/10.1001/jama.289.19.2560

[9] Chalmers, J., Macmachon, S., Mancia, G., Whitworth, J., Beilin, L., Hansson, L., Neal, B., Rodgers, A., Mhurchu, C.N. and Clark, T. (1999) 1999 World Health Organization-International Society of Hypertension Guidelines for the Management of Hypertension. Clinical and Experimental Hypertension, 21, 1009-1060.

https://doi.org/10.3109/10641969909061028

[10] Haffner, S.M., Miettinen, H., Gaskill, S.P. and Stern, M.P. (1996) Metabolic Precursors of Hypertension: The San Antonio Heart Study. Archives of Internal Medicine, 156, 1994-2000

[11] Hunt, S.C., Stephenson, S.H., Hopkins, P.N. and Williams, R.R. (1991) Predictors of an Increased Risk of Future Hypertension in Utah. A Screening Analysis. Hypertension, 17, 969-976. https://doi.org/10.1161/01.HYP.17.6.969

[12] Anuurad, E., Shiwaku, K., Nogi, A., et al. (2003) The New BMI Criteria for Asians by the Regional Office for the Western Pacific Region of WHO Are Suitable for Screening of Overweight to Prevent Metabolic Syndrome in Elder Japanese Workers. Journal of Occupational Health, 45, 335-343. https://doi.org/10.1539/joh.45.335

[13] Hanlon, P., Byers, M., Wilding, J.P.H. and Macdonald, H.M. (2014) Environmental and Nutritional Factors in Disease. In: Walker, B.R., Colledge, N.R., Ralston, S.H. and Penman, I.D., Eds., Davidson's Principles and Practice of Medicine, 22nd Edition, Churchill Livingstone, London, 97-132.

[14] Kotchen, T.A. (2008) Hypertensive Vascular Disease. In: Fauci, A.S., Braunwald, E., Kasper, D.L., Hauser, S.L., Longo, D.L. and Jameson, J.L., Eds., Harrison's Principles of Internal Medicine, 17th Edition, McGraw-Hill Companies, New York, 1549-1562.

[15] Bloomfield, P., Bradbury, A., Grubb, N.R., et al. (2011) Cardiovascular Disease. In: Colledge, N.R., Walker, B.R. and Ralstone, S.H., Eds., Davidson's Principles \& Practice of Medicine, 22nd Edition, Churchill Livingstone, London, 607.

[16] Wang, T.J., Ramchandan, S. and Vasan, R.S. (2005) Epidemiology of Uncontrolled Hypertension in the United States. Circulation, 112, 1651-1662.

https://doi.org/10.1161/CIRCULATIONAHA.104.490599

[17] Center for Disease Control and Prevention (CDC) (2005) Racial/Ethnic Disparities in Prevalence, Treatment and Control of Hypertension-United States, 1999-2002. Morbidity and Mortality Weekly Report, 54, 7-9.

[18] Wolf-Maier, K., Cooper, R.S., Banegas, J.R., et al. (2003) Hypertension Prevalence and Blood Pressure Levels in 6 European Countries, Canada and the United States. JAMA, 289, 2363-2369. https://doi.org/10.1001/jama.289.18.2363

[19] Hertz, R.P., Unger, A.N., Cornell, J.A., Saunders, E., et al. (2005) Racial Disparities in Hypertension Prevalence, Awareness and Management. Archives of Internal Medicine, 165, 2098-2104. https://doi.org/10.1001/archinte.165.18.2098

[20] Poulter, N.R., Khaw, K.T., Hopwood, B.E., Mugambi, M., Peart, W.S., Rose, G. and 
Sever, P.S. (1990) The Kenyan Luo Migration Study: Observation on the Initiation of a Rise in Blood Pressure. BMJ, 300, 967-972. https://doi.org/10.1136/bmj.300.6730.967

[21] Stavig, G.R., Igra, A. and Leonard, A.R. (1998) Hypertension and Related Health Issues among Asians and Pacific Islanders in California. American Journal of Epidemiology, 103, 28-37.

[22] Jalal, S., Sofi, F.A., Alai, M.S., et al. (2001) Prevalence of Microalbuminuria in Essential Hypertension: A Study of Patients with Mild to Moderate Hypertension. Indian Journal of Nephrology, 11, 6-11.

[23] Sayeed, M.A., Banu, A., Haq, J.A., et al. (2002) Prevalence of Hypertension in Bangladesh: Effect of Socioeconomic Risk Factor on Difference between Rural and Urban Community. Bangladesh Medical Research Council Bulletin, 28, 7-18.

[24] Zaman, M.M. and Rouf, M.A. (1999) Prevalence of Hypertension in Bangladeshi Adult Population. Journal of Human Hypertension, 13, 547-549. https://doi.org/10.1038/sj.jhh.1000838

[25] Bhavani, B.A., Padma, T, and Sastry, B.K.S. (2003) Plasma Lipoproteins (A) Levels in Patients with Untreated Essential Hypertension. Indian Journal of Human Genetics, 9, 65-68.

[26] Eaton, C.B., Feldman, H.A., Assaf, A.R., et al. (1994) Prevalence of Hypertension, Dyslipidaemia and Dyslipidaemic Hypertension in Canada. The Journal of Family Practice, 38, 17-23.

[27] Johnon, M.L., Pietz, K., Battlemen, D.S., et al. (2004) Prevalence of Co-Morbid Hypertension and Dyslipidaemia and Associated Cardiovascular Disease. American Journal of Managed Care, 10, 926-932.

[28] Gardes, J., Bouhnik, J., Clauser, E., Corvol, P. and Menard, J. (1982) Role of Angiotensinogen in Blood Pressure Homeostasis. Hypertension, 4,185-189. https://doi.org/10.1161/01.HYP.4.2.185

[29] Sutters, M. (2009) Systemic Hypertension. In: Mcphee, S.J. and Papadakis, M.A., Eds., Current Medical Diagnosis and Treatment, McGraw Hill, New York, 376-403.

[30] Julian, D.G., Campbell-Cowan, J. and McLenachan, J.M. (2004) Cardiology. 8th Revised Edition, Saunders (W.B.) Co. Ltd., Philadelphia.

[31] Field, M.J., Burnett, L., Sullivan, D.R. and Stewart, P. (2010) Clinical Biochemistry and Metabolism. In: Colledge, N.R., Walker, B.R. and Ralstone, S.H., Eds., Davidson's Principles and Practice of Medicine, 22nd Edition, Churchill Living Tone, London, 449-456.

[32] Gunnar, H.A. (1999) Effect of Age on Hypertension. Analysis of Over 4800 Referred Hypertensive Patients. Saudi Journal of Kidney Diseases and Transplantation, 10, 286-297.

[33] Yin, R.X., Wu, J.Z., Pan, S.L., Lin, W.X., Yang D.Z. and Chen Y.M. (2008) Sex Differences in Environmental and Genetic Factors for Hypertension. The American Journal of Medicine, 121, 811-819. https://doi.org/10.1016/j.amjmed.2008.04.026

[34] Billal, A., Ahsan, H.N., Ziaul, I., et al. (2007) Pattern of Lipid Profile and Obesity among Secretariat Employees of Bangladesh. Journal of Medicine, 10, 3-6.

[35] Tuan, N.T., Adair, L.S., Suchindran, C.M., et al. (2009) The Association between Body Mass Index and Hypertension Is Different between East and Southeast Asians. The American Journal of Clinical Nutrition, 89, 1905-1912. https://doi.org/10.3945/ajcn.2008.26809

[36] Kannel, W.B. (2005) Risk Stratification of Dyslipidemia: Insight from the Framing- 
ham Study. Current Medicinal Chemistry_Cardiovascular \& Hematological Agents, 3, 187-193. https://doi.org/10.2174/1568016054368250

[37] Idemudia, J. and Ugwuja, E. (2008) Plasma Lipid Profiles in Hypertensive Nigerians. The Internet Journal of Cardiovascular Research, 6, 122-178

[38] Bryan, W., Giuseppe, M., Wilko, S., et al. (2018) 2019 ESC/ESH Guidelines for the Management of Arterial Hypertension. The Task force for the Management of Arterial Hypertension. European Heart Journal, 39, 3021-3104.

[39] Kesteloot, H., Lee, C.S., Park, H.M., et al. (1982) A Comparative Study of Serum Lipid between Belgium and Korea. Circulation, 65, 795-799. https://doi.org/10.1161/01.CIR.65.4.795

[40] Amodu, P.H.O., Mbah, I.O.M. and Lovett, L. (2005) Prevalence of Obesity and Dyslipidaemia Seen in Abuja, Nigeria. Scandinavian Journal of Clinical and Laboratory Investigation, 240, 14-17. https://doi.org/10.1080/00365510500236069 


\section{Appendix-A}

\section{List of Abbreviation}

- $\mathrm{TC}=$ Total cholesterol.

- $\mathrm{TG}=$ Triglycerides.

- LDL-C = Low density lipoprotein-cholesterol.

- HDL-C = High density lipoprotein-cholesterol.

- $\mathrm{BMI}=$ Body mass index .

- $\mathrm{HTN}=$ Hypertension.

- $\mathrm{BP}=$ Blood pressure.

- $\mathrm{SBP}=$ Systolic blood pressure.

- $\mathrm{DBP}=$ Diastolic blood pressure.

- $\mathrm{CVD}=$ Cardiovascular disease.

- NHANES = National health and nutritional examination survey.

- $\mathrm{ATP}=$ Adult treatment panel.

- $\mathrm{NCEP}=$ National cholesterol education programme.

- $\mathrm{CuMch}=$ Cumilla Medical College Hospital.

\section{Appendix-B}

\section{Information \& Informed Written Consent}

1) ID:

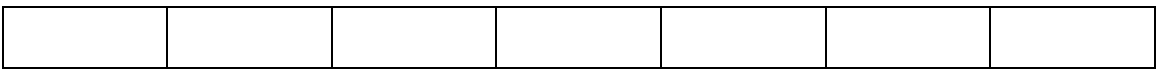

2) Evaluation of Lipid Profile in Obese and Non-obese Adult Hypertensive Patients Attended in Medicine Department of Cumilla Medical College Hospital.

3) Investigator's name: Dr. MD REAZ UDDIN CHOWDHURY

4) Institute: Cumilla Medical College Hospital, Cumilla.

5) Purpose of the study: This study is doing to correlate the lipid profile in obese and non-obese Hypertensive Adult patients presented to Medicine department of Comilla medical college hospital.

6) Selection of the participant: This study includes all adult hypertensive obese and non-obese Patients attended at Cumilla Medical College Hospital.

7) Expectation from and involvement of the participant: You will be asked some question according you are giving all will be correct

8) Risk and benefit: There is no risk of you as it will collect only verbal information and small amount of fasting venous blood.

9) Privacy, anonymity and confidentiality: You are ensured that all information should be kept confidential and you are labile to choose time and place which will be suitable for you.

10) Right to withdraw: You are free to take part or refuse any part of the study. If you agree to our proposal of enrolling you/your patient in our study, Please indicate that by putting your signature at the specified below

Signature of the participant signature of investigator 